\title{
Teaching What We Know: \\ The Influence of Pre-service EFL Teachers' Background on L2 Reading Attitudes*
}

\author{
Dennis Murphy Odo \\ (Pusan National University)
}

\begin{abstract}
Murphy Odo, Dennis. (2017). Teaching What We Know: The Influence of Pre-service EFL Teachers' Background on L2 Reading Attitudes. Language Research, 53.1, 163-190.
\end{abstract}

\begin{abstract}
Some aspects of Korean English teachers' background such as the experience as second language readers may have shaped their attitudes toward English reading in less than favorable ways. Therefore, the primary aim of this research was to investigate how Korean EFL teachers' background variables which include their L2 reading proficiency, access to English books for pleasure reading and their teaching experience relate to affective aspects of their L2 reading attitudes. To address these aims, a two-part L2 reading attitude survey was administered to 29 pre-service Korean EFL teachers. Results were that those with higher L2 reading proficiency are more comfortable reading in English, but there was no difference in comprehension ability and anxiety regarding L2 reading. Thus, it appears some aspects of attitude are more affected by $\mathrm{L} 2$ reading proficiency than others. Amount of teaching experience was found not to affect the participants' levels of comfort or anxiety when reading in English. In accordance with other studies, those who reported having access to English books available to read for pleasure were more comfortable and less anxious about reading in English than those who indicated that they did not. This finding demonstrates that simply having L2 books available can make a difference in pre-service teachers' L2 reading attitudes.
\end{abstract}

Keywords: English as a foreign language; foreign language reading; reading attitudes; pre-service English teachers

* I am thankful to the three anonymous journal reviewers for their insightful comments, constructive criticisms, and thoughtful suggestions on previous versions of this paper. Any remaining faults or omissions are mine. 


\section{Introduction}

Researchers have traditionally emphasized the cognitive aspects of reading without paying as much attention to the affective component (Afflerbach \& Cho, 2011) but we need to deepen our understanding of the affective aspect of reading because "students with negative attitudes toward second language reading are unlikely to be motivated to do the reading they need to do to become fluent readers" (Bamford \& Day 1998, p. 4). In other words, ignoring the role of attitude in L2 reading research disregards a key component of the reading experience that prompts students to do the practice they need to become competent readers.

This issue is particularly salient in the Korean EFL context where many current Korean English teachers' experiences as students fostered somewhat negative attitudes to reading in English. As students, these teachers typically followed a grammar-translation and intensive reading based approach in reading instruction that involves in-depth analysis and word-for-word translation of short texts without any pleasure reading (Byun, 2009, 2010). This instructional approach can have negative effects on Korean learners' attitudes toward reading (Cho, 2007; Song \& Lim, 2010) that can be carried over to their teaching (McKenna, Kear \& Ellsworth, 1995).

These negative attitudes stemming from prior experiences reveal themselves when many adult Koreans would rather avoid reading unless it serves their career or academic goals (Kim, 2011). Likewise, research on Korean English teachers showed that many are "clearly not dedicated pleasure readers in English" (Cho, 2013, p. 28). This finding is disconcerting because the teachers' mindset affects the student's reading attitude (Dreher 2002; Routman, 2003). Indeed, Gambrell (1996) contends that "one of the key factors in motivating students to read is a teacher who values reading and is enthusiastic about sharing a love of reading with students" (p. 20).

Although the issue has not yet received much attention in second-language research, a number of scholars investigating first-language reading teachers have begun to raise concerns about teachers being 
"alliterate" (i.e., able to read but disliking reading) themselves. Applegate and Applegate (2004) explored the reading attitudes of pre-service first-language reading teachers and found that $48 \%$ of pre-service teachers in their survey were "reluctant readers." From these results, they identified a "Peter Effect" whereby teachers are unable to impart a love for reading that they do not have. Follow up research continues to show a conspicuous lack of enthusiasm for reading among in-service and preservice teachers (Nathanson, Pruslow, \& Levitt, 2008; Applegate, et al., 2014) indicating that the Peter Effect persists.

Attitudes also require more research attention because they have been found to impact peoples' behavior (Ajzen, 2005). For instance, reading attitude was found to have "a significant positive effect on reading behavior, even if the sociodemographic variables and the amount of spare time are factored out" (Stokmans, 1999, p. 258). Attitude also relates to learners' level of activity in their language learning. Accordingly, attitudinal variables affect whether a learner will persevere in language study even more than aptitude, proficiency or achievement (Gardner, 1985). Nevertheless, the relationship between attitude and behavior is somewhat complicated. Ajzen (2005) notes that the more general the attitude we are seeking to understand, the less predictive it will be of someone's specific behaviors. As well, the impact of attitude on actual behavior can be heavily mitigated by the circumstances under which the behavior takes place.

It is important to also understand that attitudes are shaped by beliefs but targeted messages can change beliefs, attitudes and behavior (Ajzen, 2005; Day \& Bamford, 1998). This observation matters because, ultimately, researchers strive to understand the various components of language learners' attitudes and how they interrelate so that we might discover ways to cultivate more positive and productive attitudes toward language teaching and learning. Thus, the research described below hopes to contribute to positive changes in learner behavior by affecting positive changes in learner attitude. 


\section{Background}

\subsection{Reading Ability and Attitude}

McKenna, Kear and Ellsworth (1995) speculated that frustration resulting from continued negative reading experiences eventually leads to a negative attitude toward reading which they hypothesize grows worse over time for weaker readers "so that the relationship between ability and attitude should grow stronger" (p. 939). This conjecture was supported by their research with a national sample of first-language elementary school readers. Results revealed that "[increasingly] negative recreational attitude is clearly related to ability, and the trend is most rapid for least able readers" (p. 952). Kush et al. (2005) agree that our reading attitudes are slowly constructed across time as we experience success and failure while interacting with various kinds of text. They conclude that "...while reading attitude and achievement may appear unrelated at the early stages of reading they become more closely linked over time, developing into important causal determinants of reading achievement by early adolescence" (Kush, Watkins and Brookheart, 2005, p. 29).

Another first-language study with primary-school aged learners reported that there was in fact a relationship between reading ability and attitude but that it was only the case for boys and not girls (Logan \& Johnston, 2009). Studying L2 learners, Sani and Zain (2011) agreed that girls did demonstrate significantly better attitudes and comprehended significantly better. However, they also point out that more careful analysis reveals that girls' attitudes are actually neutral rather than positive. They conclude that this "...clearly indicated that the lack of enthusiasm for reading in English beyond the classroom applied to both boys as well as girls" (p. 250). Thus, at least in an EFL context, though there is a significant gender gap in reading attitudes that does not necessarily imply that girls' attitudes are positive.

A number of other second language reading studies also observe a relationship between reading attitudes and reading proficiency. For instance, Sani and Zain (2011) found a high correlation between reading attitude and reading ability which demonstrated that $\mathrm{L} 2$ reading attitude had a 
significant impact on reading improvement in an ESL setting. Analogous findings were reported for Lebanese EFL middle school students in that "learners with positive attitudes towards reading are more likely to … comprehend reading material better than their counterparts who have less positive reading attitudes" (Ghaith \& Bouzeineddine, 2003, p. 115). Investigating post-secondary learners of Japanese as a foreign language, Kondo-Brown (2006) noted that motivation intensity was moderately yet directly associated with reading comprehension ability in Japanese.

Attitudes have been linked to reading strategy use as well. McCrudden, Putney, and Perkins (2005) found that reading instruction increased learners' self-efficacy beliefs and interest in reading. From this result, they argued that strategy instruction would give learners the perseverance they need to complete challenging reading tasks and accumulate the quantity of practice time they would need to progress. A study of ESL college students reported results that attitudes toward the L1 and readers' beliefs about reading influenced their L2 reading strategy use "....although the extent to which reading behavior transfers seems to depend on the text's complexity or reader's level of proficiency in the language of the text" (Kamhi-Stein, 2003, p. 61-62). Thus, reader attitudes affect their reading behavior in ways that can contribute to their L2 reading proficiency development.

Not all investigators who explored the connections between reading attitudes and reading ability arrived at the same conclusions. In one investigation of postsecondary English learners, Yamashita (2004) found that "L2 proficiency does not have a strong influence on reading attitudes" (p. 10). Likewise, college students of French as a foreign language demonstrated that $\mathrm{L} 2$ reading self-efficacy was positively related to reading proficiency, whereas reading anxiety was not related (Mills, Pajares \& Herron, 2006). That is, the relationship between reading attitude and reading proficiency may be somewhat complex in the sense that the absence or presence of a relationship could be related to the particular aspect of attitude being investigated. For instance, it may be possible that one aspect of an L2 reader's attitude (e.g., self-efficacy) may correlate with reading proficiency while another aspect (e.g., anxiety) does not. 


\section{Teaching Experience and Attitudes}

The bulk of current research related to the connection between teaching experience and attitudes centers on teacher self-efficacy and teaching experience. A number of studies report a positive relationship between self-efficacy and teaching experience. For example, some research concludes that there are significant differences between novice and experienced teachers in their self-efficacy beliefs such that the more teaching experience the teacher has the greater his or her teacher self-efficacy belief tended to be (Ross, 1998; Wilson \& Tan, 2004). Reflecting on survey findings for elementary teachers, Soodak and Podell (1997) noted that, in contrast to high school teachers, whose self-efficacy did not change much, elementary teachers experienced a dramatic drop in their personal efficacy as they started their first year of teaching but their levels of self-efficacy rebounded as they gained additional teaching experience. Yeo et al. (2008) investigated secondary school teachers in Singapore and learned that years of professional experience positively affected their views on their abilities to teach, manage the class and maintain student interest. Another study with primary teachers in Hong Kong and Shanghai yielded comparable results. Based on the study's findings, the author contends that teachers' increased self-efficacy might be "due to the experiences that in-service teachers have accumulated in handling different challenging situations in schools and classrooms" (Cheung, 2008, p. 116). However, a more recent study points out that while teachers grew in self-efficacy over time "...their sense of efficacy to perform within certain teaching expectations was task specific and highly situated" (Faez \& Valeo, 2012, p. 450). That is, their sense of self-efficacy appeared to be closely related to particular teaching tasks and contexts and so change might affect self-efficacy.

Not all scholars agreed that increased teaching experience led to greater self-efficacy. Other research points to there being limited change in efficacy beliefs with additional teaching experience. One study of Venezuelan EFL teachers reported that there were no correlations between self-perceived efficacy for various aspects of classroom practice such as instructional 
strategies and years of English teaching experience (Chacón, 2005). Other investigators in first-language contexts concluded that in-service teachers' self-efficacy tends to be stable and difficult to alter as they accumulate additional teaching experience (Pajares, 1992; Woolfolk Hoy \& Murphy, 2001; Soodak \& Podell (1997). These findings suggest that experienced teachers beliefs of personal efficacy are more resistant to change.

Some findings even point toward experience actually leading to increasingly negative perceptions of teaching and learning. Ghaith and Shaaban (1999) found that beginning Lebanese teachers demonstrated more concern for their professional practice than their highly experienced colleagues. Most surprisingly, they noted that "teachers with more than 15 years of experience were less concerned about all the categories of teaching concerns than their beginning and experienced counterparts..." (p. 495). Thus, it appears that the most highly experienced appeared to care the least about their work. Ghaith and Yaghi (1997) similarly report that experienced teachers viewed innovative classroom practices like cooperative learning as difficult and unimportant and they tended to blame their circumstances for their perceived inability to encourage student learning. The most experienced teachers approved of outdated grammar-translation methods to teach reading more and favored communicative activities less than their junior colleagues. Senior teachers' professional practice was also less influenced by their own language learning, colleagues, and student expectations than their juniors (Gorsuch, 2001). These findings indicate that experience may not always foster greater self-efficacy or positive attitudes. In fact, at least in some circumstances, just the opposite is possible.

As the foregoing discussion demonstrates, the relationship between teaching experience and attitude related variables is somewhat complex. On the one hand, there are findings that point to a positive relationship between attitude variables and teaching experience such that those with more experience also have greater self-efficacy. However, other research has claimed that experience has a limited impact on attitude variables or even that experience can even cultivate negative attitudes and perceptions in teachers. As these varied and conflicting findings reveal, the rela- 
tionship between teaching experience and attitude variables is complex and additional research is certainly needed to help provide a more nuanced understanding of how teaching experience connects to affective variables.

\section{Teachers' Reading Attitude and Reading Experience}

The relationship between access to books and reading attitudes has received some research attention with $\mathrm{L} 1$ readers. One strand of research has looked at the impact of book availability on reading attitudes. In this research, book ownership has been shown to correlate with frequency of reading which the researchers accepted as an indicator of reading motivation (McQuillian \& Au, 2001). In fact, McQuillian and Au (2001) note that "...it is not SES [socioeconomic status] differences per se that lead to variations in reading ability among students, but rather the factors typically associated with SES, such as the amount of access students have to reading materials and the subsequent increased amount of reading done" (p. 244). That is, SES only really seems to matter because it enables access to more books.

Related research has established that access to books at home promotes more frequent recreational reading (Nieuwenhuizen, 2001), reading for longer, more confidence, and improves learners' attitudes toward reading (Clark \& Poulton, 2011). This appears to be particularly for boys even more so than girls (Merga, 2015). Likewise, other research indicates that "the presence of parental home libraries $\cdots$ and student home libraries ... significantly related to a positive attitude toward reading" (Partin \& Hendricks, 2002, p. 70). Family members also influence learners' interest in reading by showing them that "...reading can be an entertaining, diverting, enjoyable, sociable, and, therefore, worthwhile activity" (Strommen \& Mates, 2004, p. 183). Thus, there is an impact of access to books in the home and encouragement to read on attitudes toward reading. Although almost none of these studies addressed teachers specifically, one study revealed that teachers who grew up in print poor environments indicated that they were not as enthusiastic readers as those who were 
raised in print rich environments (Lao, 2003 cited in Krashen, 2011). This result hints at the importance of book access for teachers.

Access to a well-supplied classroom and/or school library has also been found to result in more reading (Krashen 2004; McQuillian \& Au, 2001). As well, availability of public libraries leads to more reading (Krashen, 2004; McQuillian \& $\mathrm{Au}, 2001$, p. 241). In fact, a single trip to the library was found to significantly improve learners' attitudes toward reading and books (Ramos \& Krashen, 1998). In one study of readers and nonreaders observed that one notable distinction between readers and nonreaders was that the readers frequently visited the local public library or bookstores (Strommen \& Mates 2004). McQuillian and Au (2001) observe that "... print access at home, in the community, and at school provide evidence that the availability of reading resources is associated with more self-reported free reading, independent of reading ability" (p. 244). All of these findings support the conclusion that greater access to reading materials enables more reading, improved reading ability and better attitudes toward reading.

At present, limited research exists on the impact of access to reading materials on learner reading proficiency or attitude improvement in second or foreign language contexts. The most closely-related literature that could be identified relates to the impact of extensive rating (ER) on L2 reading attitudes. A few studies have been conducted on Korean teachers and ER. If given the chance to try ER, teachers seem to enjoy it and a short intervention can have a relatively long-term impact on teachers' thinking. Byun (2010) investigated in-service secondary Korean EFL teachers' perceptions of ER after they tried it for two weeks. The survey and interview results revealed that the participants held more positive attitudes toward reading. Another study of in-service Korean EFL teachers revealed that the participants read between 5 and 15 books over two weeks. Some teachers even requested to make most of the class into an ER trial. A few even went out and bought their own materials to read on their own time (Cho, 2013). A follow up study determined that "70\% of the teachers had implemented sustained silent reading (SSR) in their English as a foreign language class" (Cho, 2014, p. 13). The author thus concluded that 
a short exposure to ER can have a long-term impact of teachers' beliefs and behavior regarding ER.

As the studies discussed in this section illustrate, compared to a relative wealth of literature on motivation to communicate in a second language, there is little research on affective variables like attitude and motivation in L2 reading (Bamford \& Day, 1998). This particularly appears to be the case in EFL settings (Kim, 2011; Nishino, 2005; Yamashita, 2004). The bulk of the research on L2 reading has focused on cognitive aspects of reading such as decoding which presents a somewhat skewed representation of what the issues and obstacles are in teaching and learning L2 reading (Han, 2011). There should be additional exploration of the relationship between the teaching/learning of $\mathrm{L} 2$ reading and attitude because, as McKenna et al. (1995) point out, "opinions about the effects of methods and materials on attitudes are frequently expressed, but evidence is scant" (p. 941).

To better understand the relationship between affect and L2 reading, we need to pay more attention to the connection between respondents' background characteristics and their attitudes related to second-language reading. Therefore, this investigation explores the connection between several background variables including reading proficiency, access to English books, and teaching experience. These background variables serve as indicators of participants' preparedness to teach L2 reading. This study explores their relationships to particular aspects of $\mathrm{L} 2$ reading attitudes which include respondents' level of comfort and anxiety regarding reading in an L2.

Thus, the purpose of this study is to compare aspects of the attitudes toward second-language reading of well-prepared and less well-prepared pre-service English teachers in terms of their background experiences (e.g., access to English books for pleasure reading) for pre-service teachers at a Korean university. Three dimensions of the teachers' backgrounds explored in the study include their target language reading proficiency, their previous experience with L2 reading, and their teaching experience. The following questions will guide the research: (1) What are the differences in affective aspects of reading attitudes toward English reading between 
pre-service teachers with lower and higher reading proficiency? (2) How do pre-service EFL teachers who report more access to English books to read for pleasure compare with those who report less access to English books in terms of affective aspects of reading attitudes? (3) How do pre-service teachers with less than one year, one year, and more than one year of teaching experience differ in terms of the affective aspects of their $\mathrm{L} 2$ reading attitudes?

\section{Methodology}

\subsection{Participants}

The data was collected for this study in the spring of 2016. Twenty-nine Korean undergraduate students majoring in English education in their $3^{\text {rd }}$ and $4^{\text {th }}$ year of their program (females: 23 and males: 6; mean age 23.2 years) were recruited from the Department of English Language Education at a major research university located in South Korea. On the survey used for this study, $92.9 \%$ of respondents indicated that their level of English proficiency was lower intermediate or above. They were enrolled in an academic writing class. This class was chosen because it incorporated L2 reading and writing and the research was attempting to ascertain participants' reading attitudes.

\subsection{Instrument}

A two-section reading attitudes questionnaire was used for this research. Section one was comprised of questions designed to elicit relevant background and demographic information. Items covering a range of variables were included based on factors related to reading attitude found in previous research (e.g., Day \& Bamford, 1998; Ro \& Cheng-Ling, 2014). These variables were year of study, age, gender, major, teaching experience, self-rated English reading ability, number of years studying English, experience in English-speaking countries, access to English books, and current habits regarding pleasure reading in English. 
Section two was an attitude survey adopted from Yamashita's (2007, 2013) L2 reading attitude questionnaire. The questionnaire contained five-point Likert-scale items designed to elicit participants' affective reactions toward reading in English. Two previous factor analyses demonstrated the presence of five distinct factors associated with L2 reading attitude. Two factors correlated with the affective component of reading attitude (Comfort and Anxiety) and three with the cognitive facet (Intellectual Value, Practical Value, and Linguistic Value) (Stoeckel, Reagan \& Hann, 2012). For the present study, the questionnaire was informally piloted with several Korean speakers who had comparable language ability to the participants. That is, three intermediate-level Korean English speakers were given the questionnaire and asked to comment on their ability to understand it. Only the two factors associated with the affective component of reading attitude (i.e., Comfort and Anxiety) were included in the present analysis.

\subsection{Procedures}

Participants voluntarily completed a reading attitudes survey during the first class meeting. They were asked to complete the survey at the beginning of the first class and reminded that they could abstain from participating in the research. To avoid undue peer influence on the results, they were asked to complete the survey without discussing its contents with their classmates. The survey took 10-15 minutes to complete.

\subsection{Scoring and Analysis}

Factor analysis could not be performed to detect underlying factors due to insufficient sample size. Nevertheless, based upon positive findings from Yamashita's (2013) previous analyses, her suggested multi-item scales were used in this study as well. Items 3, 9, 13, 16, 18, and 21 were included in the multi-item scale designated as "Comfort." Items 5, 10, 17, and 20 were grouped into the index labelled "Anxiety." Likert items in the questionnaire were generally constructed so that selection of a five indicated a greater amount of anxiety than four. Accordingly, values for 
negatively-worded items were recoded so high scores consistently designated the presence of more of the trait (e.g., anxiety) being investigated.

Data normality was checked by visually examining a histogram of the sample and comparing it to a normal probability curve. A visual inspection of the histogram revealed that scores appeared to resemble a normal distribution. Additionally, a Shapiro-Wilks test rejects the hypothesis of normality when the p-value is less than or equal to 0.05 . The obtained $\mathrm{p}$-values revealed that there was not a significant departure from normality in the data. A follow up quantile-quantile plot of the standardized data against the standard normal distribution revealed the correlation between the sample data and normal quantiles showed that the points plotted in the QQ plot fell approximately on a straight line, indicating high positive correlation thus showing that the data fit the normal distribution. All tests of normality revealed minimal departure from normality in the data. Thus, all data were used in the final analysis.

The attitude survey administered at the outset of the course yielded the results presented in table 1. Cronbach's alpha results revealed that both scales were reliable. Acceptable values for Cronbach's alpha generally range between .7 and .8 (Kline, 1999, cited in Field, 2006). Statistical data analysis for the Reading Attitudes Questionnaire consisted of performing a series of independent t-tests that compared respondents' indicated scores on the affective subscales of the questionnaire in terms of their background variables such as their reading proficiency and access to English books to read for pleasure.

\section{Results}

As an indicator of L2 reading attitude, the present study calculated the mean scores for the questionnaire items related to each of the multi-item scales (i.e., comfort and anxiety). Items that assessed respondents' self-perceived levels of tension associated with L2 reading were grouped into a multi-item scale labeled "comfort." Items associated with respondents' self-reported apprehension levels for L2 reading were collected 
into the multiple-item index known as "anxiety." Table 1 below shows the descriptive statistics for each multi-item scale.

Table 1. Descriptive Statistics and Cronbach's Alpha Coefficients for Attitude Variables $(\mathrm{n}=29)$

\begin{tabular}{c|c|c}
\hline & Comfort & Anxiety \\
\hline \hline Mean & 3.259 & 3.353 \\
\hline SD & 0.633 & 0.907 \\
\hline Skewness & -0.483 & -0.296 \\
\hline Kurtosis & 0.516 & -1.285 \\
\hline Minimum & 1.500 & 2.000 \\
\hline Maximum & 4.330 & 4.750 \\
\hline$a$ & .81 & .75 \\
\hline
\end{tabular}

RQ 1: What are the differences in affective aspects of reading attitudes toward English reading between pre-service teachers with lower and higher reading proficiency?

An independent-samples t-test was conducted to compare participants' affect in terms of their level of comfort and anxiety when reading in English in terms of their self-rated general comprehension level when they read in English. The two groups were divided into average comprehenders and good/ very good comprehenders. With respect to their level of comfort with English reading, there was a significant difference in the scores for average comprehenders $(\mathrm{M}=3.063, \mathrm{SD}=0.607)$ and good/ very good comprehenders $(\mathrm{M}=3.632, \mathrm{SD}=0.525) ; \mathrm{t}(27)=-2.507, \mathrm{p}$ $=.018$. These results indicate that those who saw themselves as good or very good comprehenders reported being significantly more comfortable with English reading than those who saw themselves as average comprehenders. Thus, it appears that those with higher reading proficiency are more comfortable reading in English.

A second independent-samples t-test was performed to ascertain whether there were significant differences in participants' levels of anxiety associated with reading in English depending on their self-rated general English 
reading comprehension level. Results demonstrated no significant difference in scores for average comprehenders $(\mathrm{M}=3.513, \mathrm{SD}=0.864)$ and good/ very good comprehenders $(\mathrm{M}=3.050, \mathrm{SD}=0.956) ; \mathrm{t}(27)=1.324$, $p=.197$. These results show that there is no difference in participants' level of English reading anxiety according to their self-rated overall English reading comprehension level. Accordingly, it appears that there is less of a relationship between reading comprehension ability and anxiety regarding L2 reading.

Table 2. Descriptives Statistics for Comprehension

\begin{tabular}{c|c|c|c|c|c}
\hline & Group & $\mathrm{N}$ & Mean & SD & SE \\
\hline \hline \multirow{2}{*}{ Comfort } & average & 19 & 3.063 & 0.607 & 0.139 \\
\cline { 2 - 6 } & good & 10 & 3.632 & 0.525 & 0.166 \\
\hline \multirow{2}{*}{ Anxiety } & average & 19 & 3.513 & 0.864 & 0.198 \\
\cline { 2 - 6 } & good & 10 & 3.050 & 0.956 & 0.302 \\
\hline
\end{tabular}

RQ 2: How do pre-service teachers with less than one year, one year, and more than one year of teaching experience differ in terms of the affective aspects of their $\mathrm{L} 2$ reading attitudes?

A one-way between subjects ANOVA was conducted to compare the effect of teaching experience on level of comfort reading in English in less than one year, one year, and over one year conditions. Results revealed that there was not a significant effect of teaching experience on comfort reading in English at the $\mathrm{p}<.05$ level for the three conditions $[\mathrm{F}(2,26)$ $=0.460, \mathrm{p}=.637]$.

A second one-way between subjects ANOVA was performed to compare the effect of teaching experience on level of anxiety with reading in English in less than one year, one year, and over one year conditions. Results demonstrated no significant effect of teaching experience on anxiety with reading in English at the $\mathrm{p}<.05$ level for the three conditions $[\mathrm{F}(2,26)$ $=0.561, \mathrm{p}=.577]$.

The attitude-related construct of self-efficacy has been shown to be affected by teaching experience so it seemed possible that other affective 
facets of L2 reading attitudes like comfort with reading and anxiety regarding reading might be affected by teaching experience. However, these results suggest that teaching experience does not have an effect on level of comfort or anxiety when reading in English. That is, these participants' amount of prior teaching experience does not influence their levels of comfort or anxiety when they read in their second language, English. Thus it appears that teaching experience does not necessarily improve teachers' comfort levels or anxiety regarding L2 reading. Given the impact that teacher attitudes have been shown to have on learner attitudes (Dreher 2002; Routman, 2003), this finding is not encouraging.

RQ 3: How do pre-service EFL teachers who report more access to English books to read for pleasure compare with those who report less access to English books in terms of affective aspects (i.e., comfort and anxiety) of reading attitudes?

A significant difference was observed between those who never or rarely had access to books for pleasure reading $(\mathrm{M}=2.981, \mathrm{SD}=0.624)$ and those who sometimes or often had access to pleasure reading materials $(\mathrm{M}=3.602, \mathrm{SD}=0.468)$ in terms of their comfort with $\mathrm{L} 2$ reading $\mathrm{t}(27)$ $=-2.966, \mathrm{p}=.006$. This means that those who report having access to English books to read for pleasure are significantly more comfortable with reading in English than those who indicated that they did not.

Likewise, a significant difference in English reading-related anxiety was found between those with limited access to books for pleasure reading $(\mathrm{M}=3.844, \mathrm{SD}=0.670)$ and those with greater access to pleasure reading materials $(\mathrm{M}=2.750, \mathrm{SD}=0.804)$ in terms of their comfort with $\mathrm{L} 2$ reading $\mathrm{t}(27)=3.999, \mathrm{p}<.001$. These findings show those who report having more access to English books to read for pleasure are significantly less anxious about reading in English than those with limited access. In other words, those with more opportunities to read for pleasure tend to be less anxious when it comes to reading in English. 
Table 3. Descriptive Statistics for Book Access

\begin{tabular}{c|c|c|c|c|c}
\hline & Group & $\mathrm{N}$ & Mean & SD & SE \\
\hline \hline \multirow{2}{*}{ Comfort } & Less & 16 & 2.981 & 0.624 & 0.156 \\
\cline { 2 - 6 } & More & 13 & 3.602 & 0.468 & 0.130 \\
\hline \multirow{2}{*}{ Anxiety } & Less & 16 & 3.844 & 0.670 & 0.168 \\
\cline { 2 - 6 } & More & 13 & 2.750 & 0.804 & 0.223 \\
\hline
\end{tabular}

\section{Discussion}

\subsection{Reading Proficiency and L2 Reading Affect}

Results related to the connection between reading proficiency and attitudes indicate a somewhat complex relationship. On the one hand, somewhat predictably participants who self-rated that they had a higher general English reading proficiency were also found to be are more comfortable reading in English. However, unexpectedly self-rated overall English reading comprehension level had no significant effect on participants' level of English reading anxiety. Thus, it seems that the existence of a connection between self-rated proficiency and attitude depends on the aspect of attitude being measured.

These results correspond to findings from some previous research that observed a connection between L2 reading proficiency and attitudes. Results with EFL middle school students indicated that reading attitudes and reading achievement were related in that "learners with positive attitudes towards reading are more likely to ${ }^{-\cdots}$ comprehend reading material better than their counterparts who have less positive reading attitudes" (Ghaith \& Bouzeineddine, 2003, p. 115). Another study of EFL high school students reported that more positive attitudes towards reading in English were associated with stronger reading ability (Sani \& Zain, 2011). Similarly, Kamhi-Stein (2003) demonstrated a connection between post-secondary readers' beliefs about reading their L2 reading strategy use and their L2 proficiency. University students who scored higher on Japanese L2 proficiency measures showed more positive perceptions of their own reading abilities as well revealing a mutually-influencing associa- 
tion between reading ability and motivation (Kondo-Brown, 2006).

In contrast to these confirmatory findings, other studies presented somewhat contradictory results. For instance, in the case of postsecondary English learners, Yamashita (2004) found that "L2 proficiency does not have a strong influence on reading attitudes" (p. 10). A study with college French students demonstrated that L2 reading self-efficacy was positively related to reading proficiency, whereas reading anxiety was not related (Mills, Pajares \& Herron, 2006). This result supports the finding from the present study that the association between reading attitudes and proficiency may be dependent on the aspect of attitude being measured.

In general, the bulk of existing research points to a relationship between L2 reading attitudes and L2 reading proficiency. However, this result is tempered by findings that call this relationship into question or at least show that the connection between reading proficiency and attitude may be mitigated by other factors such as the aspect of attitude being measured. Thus, one facet of attitude like comfort has been associated with reading proficiency while another like anxiety has not. The current study connects to these results to other findings by acknowledging that while there is a relationship between $\mathrm{L} 2$ reading attitudes and L2 reading proficiency this relationship appears to be influenced by the aspect of attitude being investigated. Although we may intuitively believe that all characteristics of attitude correlate with reading proficiency, these results demonstrate this not to be the case. Accordingly, future investigations should tease out and explore separately the specific aspects of attitude and their relationship with reading proficiency rather than attitude overall.

\subsection{Teaching Experience and L2 Reading Affect}

Considering the influence of teacher attitudes on learner attitudes (Dreher 2002; Gambrell, 1996; Routman, 2003) and the potential negative influence of teaching experience on teacher perceptions (Ghaith \& Shaaban, 1999; Ghaith \& Yaghi, 1997; Gorsuch, 2001), it seemed worthwhile to study possible effects of teaching experience on teacher attitudes. Participants with under one year, one year, and over one year of teaching 
experience demonstrated no significant dissimilarities in their amounts of comfort or anxiety with L2 reading. Much of the current research literature does not deal directly with the relationship between teaching experience and teacher levels of comfort or anxiety about reading. Rather, the most closely related current research tends to center on teacher self-efficacy and teaching experience. In general, previous research results on this topic are somewhat divided.

Some studies have found self-efficacy was positively correlated with teaching experience. A number of investigators reported significant differences between novice and experienced teachers in their self-efficacy beliefs about various aspects of their classroom practice (Ross, 1998; Wilson $\&$ Tan, 2004; Yeo et al., 2008). In the case of beginning teachers, Faez and Valeo (2012) note that "[teaching] experience, in general, increases teachers' perceived sense of preparedness" (p. 458). However, in the case of these novice teachers, " $\cdots$ their sense of efficacy to perform within certain teaching expectations was task specific and highly situated" ( $p$. 450). Research with experienced teachers found that more experience was associated with teacher self-efficacy which the author speculates might relate to "... experiences that in-service teachers have accumulated in handling different challenging situations in schools and classrooms" (Cheung, 2008, p. 116).

Other research arrives at conflicting conclusions. One study concluded that there is limited change in efficacy beliefs with additional teaching experience (Chacón, 2005). The author reported that there was no correlation between self-efficacy beliefs and years of English teaching experience so teachers' efficacy beliefs did not change much as they accumulated additional teaching experience. This result corroborates other studies that state teachers' self-efficacy beliefs tend to be difficult to alter after they are formed (Pajares, 1992; Woolfolk Hoy \& Murphy, 2001) and that they in fact may become more resistant to change with experience (Soodak \& Podell, 1997).

According to some research, one hazard that appears to accompany experience is that in some instances veteran teachers have developed negative perceptions of teaching and learning. For instance, highly experi- 
enced teachers have been found to show less concern about their teaching than their beginning and experienced colleagues (Ghaith \& Shaaban, 1999). Furthermore, some veteran teachers have also become more resistant to continued development. That is, those with more teaching experience viewed current communicative methods as difficult and unimportant (Ghaith \& Yaghi, 1997; Gorsuch, 2001). They were also less receptive to outside influences like student expectations to change their teaching practices than their juniors (Gorsuch, 2001).

Unlike previous research that explored connections between experience and teacher self-efficacy, the results of the current study find no connection between the amount of experience for novice teachers and their level of affect (i.e., comfort and anxiety) when they read in English. Thus, while there does appear to be a relationship between teaching experience and self-efficacy beliefs associated with teaching, this same relationship does not appear to extend to other domains like level of comfort or anxiety associated with reading in the $\mathrm{L} 2$. That is, teaching experience seems to affect self-efficacy regarding teaching but not necessarily the content or skills being taught. Only additional research can help clarify the precise connection between amount of experience and attitudes toward the subject matter or skills being taught.

\subsection{Target Language Book Access and L2 Reading Affect}

Findings were that those with English books available to read for pleasure are more comfortable and less anxious reading in English than those without access to English books. Previous research with learners that investigated the connection between access to books at home and attitudes toward reading established that access to books at home and school results in more reading which in turn fosters learners' enthusiasm for reading (Krashen, 2004, 2011). While the relationship between access to books and positive reading attitudes may appear obvious to some, such research is necessary because without it we cannot demonstrate with certainty the powerful effect that simple availability of books can have on students' reading behavior and attitudes. 
Studies of enthusiastic readers found that they usually have greater access to books at home (Nieuwenhuizen 2001). In fact, access to books through ownership (Clark \& Poulton, 2011), purchase, receiving them as gifts, visiting libraries (Ramos \& Krashen, 1998) or sharing with family or friends as well as the curation of home libraries encourages positive attitudes toward reading (Partin \& Hendricks 2002; Strommen \& Fowles Mates, 2004) and increased engagement in recreational reading (Merga, 2015). Similarly, McQuillian and Au (2001) investigated secondary school students and found that access to reading material through classroom libraries led to more frequent reading and improved motivation across all levels of reading ability.

Not much research has explored the impact of access to reading materials on teachers' reading attitudes. However, one study with teachers demonstrates that those who grew up in print poor versus print rich environments revealed that those in print poor environments were less enthusiastic readers (Lao, 2003). In general, these results echo findings with learners that reading material access improves teachers' reading attitudes.

Other research drawing on studies of interventions with teachers that provide access to additional reading material using extensive reading shows that this practice engenders positive attitudes toward reading in the target language. Research on in-service Korean English teachers and extensive reading (ER) shows that when they have an opportunity to experience it themselves, they enjoy it and it improves their attitudes toward reading (Byun, 2010). Another study with in-service teachers who did ER during a graduate class resulted in strong positive reactions from the participants. Some read as many as 15 books in the two week span of the program and entreated the researcher to give them additional time to read (Cho, 2013). A six-month follow-up study revealed that many participants had become more dedicated to L2 pleasure reading themselves and made space for SSR in their English classes. Thus, Cho (2014) concluded that "a short (two-week) personal pleasure reading experience in English had a dramatic effect on teachers' own reading behavior and their interest in implementing sustained silent reading in their classes..." (p. 15). In these instances, having access to reading materials dramatically 
changed the teachers' feelings about L2 reading. The results of the current study concur with these findings and highlight how Korean EFL teachers' access to books has had a positive impact on their attitudes toward reading in English.

\section{Conclusions}

Findings on the relationship between self-rated proficiency and attitude indicate that the connection appears to depend on the aspect of attitude being measured. That is, participants' who self-rated their English comprehension as being higher when they read in English were also found to be are more comfortable reading in English. However, self-rated English reading comprehension level was found to have no significant effect on their level of English reading anxiety. A possible explanation for this result could be due to the fact that English reading in Korea is often tied to performance on high-stakes tests like College Scholastic Ability Test (CSAT). Consequently, reading in English may make everyone moderately anxious regardless of his or her proficiency level. Some previous research points toward a connection between $\mathrm{L} 2$ reading proficiency and attitudes while other studies claim either there is not or that it depends on the aspect of attitude being measured. Additional research can help to establish the veracity of this relationship between attitudes and proficiency or whether it does in fact depend on the aspect of attitude being measured. Further research can also more clearly identify reasons for this lack of connection between reading proficiency and reading anxiety.

The second main finding was that participants with varying amounts of teaching experience demonstrated no significant dissimilarities in their level of comfort or anxiety with L2 reading. This result echoed some prior research findings that classroom experience did not relate to teachers' sense of self-efficacy. However, as noted above, there are other research results that teaching experience may actually contribute to more negative teacher attitudes. Here as well, additional research may provide a more nuanced explanation of these apparent contradictions in the extant research. 
The final finding was that participants with English books available to read for pleasure indicated that they were more comfortable and less anxious reading in English than those without access to English books. These findings establishing that the availability of materials positively connect with participants' attitudes are in agreement with previous research that increased access to reading materials improves learners' attitudes to reading. The present research adds to prior findings by demonstrating this to also be true for non-native speaking EFL teachers as well.

\subsection{Limitations to the Study}

A number of limitations to the research encourage some caution when interpreting these results. First, participants' level of comprehension ability was self-reported rather than measured by a formal assessment. Thus, there is the possibility that they have over or under estimated their ability level thereby calling the relationship between their comprehension ability and affective variables into question so some caution must be used when interpreting the findings. As well, the sample recruited for the research was not selected based on whether it was representative of pre-service English teachers in Korea. Therefore, attempts to generalize these findings to all English teachers in Korea must be made with care.

Complex connections between language proficiency and attitude imply that the relationship between these two variables may be more complicated than has been previously assumed. For that reason, future research should incorporate more sensitive instruments to enable a nuanced understanding of the particular aspects of attitude that language proficiency influences.

Lack of a relationship between amount of teaching experience and levels of comfort or anxiety with English reading means that teaching experience does not seem to affect English teachers' attitudes toward English reading. However, given the existent controversy in the research literature, additional research should be conducted to ensure that there is in fact no significant connection between these two variables. For example, more research is needed into the effect of teaching experience on attitudes associated with the subject matter or skills being taught. As well, since the 
current student only looked at novice teachers, questions remain regarding whether the amount of experience has an impact on attitudes over a longer time period.

Lastly, more detailed and in-depth investigation is needed of the relationship between learners' access to books and their attitudes and language proficiency in EFL contexts like Korea. At present, we know that extensive reading is an effective tool for promoting positive attitudes (Jeon \& Day, 2016). However, we do not know the impact that simply having access to English books without any coercion to read might have on learners' attitudes. Currently, most of the research in this area has been conducted in English-as-a-first-language contexts. Further investigation of the role of book access could illuminate its impact on the promotion of learner L2 proficiency and positive affect in EFL contexts. It would certainly benefit teachers to know whether simply having access to comprehensible L2 reading materials would support their learners in developing more positive language learning attitudes.

\section{References}

Afflerbach, P. P. and Cho, B. Y. (2011). The classroom assessment of reading. In M. L. Kamil, P. D. Pearson, E. B. Moje, \& P. P. Afflerbach (Eds.), Handbook of Reading Research (Vol. 4, pp. 487-514). New York, NY: Routledge/Taylor \& Francis.

Ajzen, I. (2005). Attitudes, personality, and behavior. Berkshire, UK: McGraw-Hill Education.

Applegate, A. J., Applegate, M. D., Mercantini, M. A., McGeehan, C. M., Cobb, J. B., Deboy, J., Modla, V. B., and Lewinski, K.E. (2014). The Peter Effect Revisited: Reading habits and attitudes of college students. Literacy Research and Instruction 53.3, 188-204.

Bamford, J. and Day, R. R. (1998). Teaching reading. Annual Review of Applied Linguistics 18, 124-141.

Byun, J. M. (2009). Extensive reading program as an after-school program. The Journal of Mirae English Language and Literature 14, 71-97.

Byun, J. H. (2010). Korean EFL teachers' perspectives about their participation in an extensive reading program (Unpublished doctoral dissertation). The University of 
Texas at Austin, Austin Texas, USA.

Chacon, C. T. (2005). Teachers' perceived efficacy among English as a foreign language teachers in middle schools in Venezuela. Teaching and Teacher Education 21.3, 257-272.

Cheung, H. Y. (2008). Teacher efficacy: A comparative study of Hong Kong and Shanghai primary in-service teachers. The Australian Educational Researcher 35.1, 103-123.

Cho, K. S. (2007). An elementary English reading program for free reading. Journal of Language Science 14.2, 121-143.

(2013). Overcoming fear of reading in English. The astonishing impact of a short SSR experience. The International Journal of Foreign Language Teaching 7.1, 28-30.

(2014). The lasting impact of a short SSR experience on EFL teachers in Korea. The International Journal of Foreign Language Teaching 10.1, 13-15. Clark, C. and Poulton, L. (2011). Book ownership and its relation to reading enjoyment, attitudes, behaviour and attainment. London: National Literacy Trust.

Dreher, M. J. (2002). Motivating teachers to read. The Reading Teacher 56.4, 338-340.

Faez, F. and Valeo, A. (2012). TESOL teacher education: Novice teachers' perceptions of their preparedness and efficacy in the classroom. TESOL Quarterly $46.3,450-471$.

Field, A. (2006). Research Methods II: Reliability Analysis, 1-7. Available at: http://www.statisticshell.com/docs/reliability.pdf (Accessed 3 October 2016).

Gambrell, L. B. (1996). Creating classroom cultures that foster reading motivation. The Reading Teacher, 50.1, 14.

Gardner, R. C. (1985). Social psychology and second language learning: The role of attitudes and motivation. London: Arnold.

Ghaith, G. M. and Bouzeineddine, A. R. (2003) Relationship between reading attitudes, achievement, and learners' perceptions of their Jigsaw II cooperative learning experience. Reading Psychology 24, 105-121.

Ghaith, G. and Shaaban, K. (1999). The relationship between perceptions of teaching concerns, teacher efficacy, and selected teacher characteristics. Teaching and Teacher Education 15, 487-496.

Ghaith, G. and Yaghi, H. (1997). Relationships among experience, teacher efficacy, and attitudes toward the implementation of instructional innovation. Teaching and Teacher Education 13.4, 451-458.

Gorsuch, G. (2001). Japanese EFL teachers' perceptions of communicative, audio lingual and yakudoku activities: The plan versus the reality. Education Policy 
Analysis Archives, 9(10). Available: http://epaa.asu.edu/ojs/article/view/339/465 (Accessed 2 October 2016).

Han, F. (2011). Relations among motivation, reading amount, awareness of strategy use and achievement in foreign language reading. Proceedings of the 16th Conference of Pan-Pacific Association of Applied Linguistics, 232-236.

Jeon, E. Y. and Day, R. R. (2016). The effectiveness of ER on reading proficiency: A meta-analysis. Reading in a Foreign Language 28.2, 246-265.

Kamhi-Stein, L. D. (2003). Reading in two languages: How attitudes toward home language and beliefs about reading affect the behaviors of "underprepared" L2 college readers. TESOL Quarterly 37.1, 35-71.

Kim, K. J. (2011). Reading motivation in two languages: an examination of EFL college students in Korea. Reading and Writing 24.8, 861-881.

Kondo-Brown, K. (2006). Affective variables and Japanese L2 reading ability. Reading in a Foreign Language 18.1, 55-71.

Krashen, S. (2004). The power of reading. Portsmouth: Heinemann and Westport, $\mathrm{CN}$ : Libraries Unlimited.

Unlimited.

(2011). Free voluntary reading. Santa Barbara, CA: Libraries

Kush, J. C., Watkins, M. W., and Brookhart, S. M. (2005). The temporal-interactive influence of reading achievement and reading attitude. Educational Research and Evaluation 11.1, 29-44.

Lao, C. Y. (2003). Prospective teachers' journey to becoming readers. New Mexico Journal of Reading 32.2, 14-20.

McKenna, M. C., Kear, D. J., and Ellsworth, R. A. (1995). Children's attitudes toward reading: A national survey. Reading Research Quarterly 30, 934-955.

McQuillian, J. and Au, J. (2001). The effect of print access on reading frequency. Reading Psychology 22.3, 225-248.

Merga, M. K. (2015). Access to books in the home and adolescent engagement in recreational book reading: Considerations for secondary school educators. English in Education 49.3, 197-214.

Mills, N., Pajares, F., and Herron, C. (2006). A reevaluation of the role of anxiety: Self-efficacy, anxiety, and their relation to reading and listening proficiency. Foreign Language Annals 39.2, 276-295.

Nathanson, S., Pruslow, J., and Levitt, R. (2008). The reading habits and literacy attitudes of inservice and prospective teachers: Results of a questionnaire survey. Journal of Teacher Education 59.4, 313-321.

Nieuwenhuizen, A. (2001). Young Australians reading: From keen to reluctant readers. Melbourne, Victoria: Australian Centre for Youth Literature. 
Nishino, T. (2005). Japanese high school students' L2 reading motivation. Lifelong Learning: Proceedings of the 4th Annual JALT Pan-SIG Conference, 14-15.

Pajares, F. (1992). Teachers' beliefs and educational research: Cleaning up a messy construct. Review of Educational Research 62.3, 307-332.

Partin, K. and Hendricks, C. G. (2002). The relationship between positive adolescent attitudes toward reading and home literary environment. Reading Horizons 43.1, 61-84.

Ro, E. and Cheng-ling, A. C. (2014). Pleasure reading behavior and attitude of non-academic ESL students: A replication study. Reading in a Foreign Language 26.1, 49-72.

Ramos, F. and Krashen, S. (1998). The impact of one trip to the public library: Making books available may be the best incentive for reading. The Reading Teacher 51.7, 614-615.

Ross, J. A. (1998). Antecedents and consequences of teacher efficacy. In J. Brophy (Ed.), Advances in Research on Teaching (Vol. 7, pp. 49-74). Greenwich, CT: JAI Press.

Routman, R. (2003). Reading essentials: The specifics you need to teach reading well. Portsmouth, NH: Heinemann.

Murad Sani, A. and Zain, Z. (2011). Relating adolescents' second language reading attitudes, self-efficacy for reading, and reading ability in a non-supportive ESL setting. The Reading Matrix 11.3, 243-254.

Song, M. J. and Lim, J. W. (2010). A critical review of reading- and-writing-related studies in Modern English Education. Modern English Education 11.2, 60-81.

Soodak, L. C. and Podell, D. M. (1997). Efficacy and experience: Perceptions of efficacy among preservice and practicing teachers. Journal of Research and Development in Education 30.4, 214-221.

Stoeckel, T., Reagan, N., and Hann, F. (2012). Extensive reading quizzes and reading attitudes. TESOL Quarterly 46.1, 187-198.

Stokmans, M. J. (1999). Reading attitude and its effect on leisure time reading. Poetics 26.4, 245-261.

Strommen, L. T. and Mates, B. F. (2004). Learning to love reading: Interviews with older children and teens. Journal of Adolescent \& Adult Literacy 48.3, 188-200.

Wilson, P. and Tan, G. C. I. (2004). Singapore teachers' personal and general efficacy for teaching primary social studies. International Research in Geographical \& Environmental Education 13.3, 209-222.

Woolfolk Hoy, A. and Murphy, P. K. (2001). Teaching educational psychology to 
the implicit mind. In B. Torff, \& R. Sterberg (Eds.), Understanding and teaching the intuitive mind (pp. 145-185). Mahwah, NJ: Lawrence Erlbaum.

Yamashita, J. (2004). Reading attitudes in L1 and L2, and their influence on L2 extensive reading. Reading in a Foreign Language 16.1, 1-19.

(2007). The relationship of reading attitudes between L1 and L2:

An investigation of adult EFL learners in Japan. TESOL Quarterly 41.1, 81-105. (2013). Effects of extensive reading on reading attitudes in a foreign language. Reading in a Foreign Language 25.2, 248-263.

Yeo, L. S., Ang, R. P., Chong, W. H., Huan, V. S., and Quek, C. L. (2008). Teacher efficacy in the context of teaching low achieving students. Current Psychology 27.3, 192-204.

Murphy Odo, Dennis

The Department of English Language Education

Pusan National University

2, Busandaehak-ro 63 beon-gil,

Geumjeong-gu, Pusan, 46241, S. Korea

E-mail: dmodo@pusan.ac.kr

Received: February 17, 2017

Revised version received: March 29, 2017

Accepted: April 23, 2017 